\title{
1. Introduction to Teaching International Relations
}

\author{
James M. Scott, Ralph G. Carter, Brandy \\ Jolliff Scott and Jeffrey S. Lantis
}

\section{INTRODUCTION}

We are delighted to introduce this new volume on Teaching International Relations. Instructors and students alike face a complicated and increasingly interconnected world in which security, prosperity, identity, and quality of life all have international and transnational components that are growing in relevance. Engaging with our students to encourage them to understand what happens in world politics and how and why it happens is thus both important and challenging.

Our approach to this challenge rests on a philosophy of student engagement and active learning focused on efforts to facilitate subject mastery and the development of critical/analytical thinking and writing skills. As professors and mentors, we believe that the foundations of excellence in education include a participatory environment where students are engaged in and are owners of their learning and instruction occurs in an active, applied fashion. These elements help to build the substantive expertise necessary for mastery of a discipline and they encourage critical inquiry and facilitate discovery, as students are engaged in asking questions and seeking answers. We believe, and extensive research indicates, that when students are the owners of learning, they learn more and develop faster. So, teaching international relations (IR) - or any subject - in ways that emphasize student participation, discovery, critical/analytical thinking, and intellectual independence promises substantial benefits.

In this volume, we have assembled contributions from outstanding and experienced professors and mentors in IR who consider course structure and goals; classroom approaches, techniques, and activities to foster engaged learning; and assessment of teaching effectiveness and learning outcomes. Together, we share the commitment to helping students make sense of world politics, and to do so with a learner-centered, engaged approach that contrib- 
utes to both substantive mastery and a range of critical/analytical thinking, writing, and communication skills.

This introductory chapter describes the transformational era in which we are living and highlights the value of innovation in teaching and learning for a new generation of students. We identify and discuss contemporary trends and innovative approaches for the active IR classroom and the need for broad and inclusive approaches that expand perspectives. We also provide an overview of the rest of our volume that highlights the purposes, approaches, and techniques addressed in the chapters that follow.

\section{A CRITICAL TIME FOR TEACHING IR}

The world has experienced dramatic changes during just the past 20 years, or the lifetime of many of today's college students. The post-Cold War optimism of the early 1990s - based on expectations of an era of democratic peace - was soon dashed. Terrorist attacks on Western targets resulted in a Global War on Terror and seemingly never-ending conflicts in the Middle East, Africa, and Asia. A second shock was the sharp rise in intrastate wars and genocidal violence. Refugees and asylum seekers scrambled to reach safer areas by any means necessary. A third shock came in 2020 with the devastating global pandemic and its costly effects on the lives and wellbeing of people and societies around the world. These and other pressures on Western countries gave rise to an increasing number of populist or nativist political parties and backlashes against democracy in many places. Concurrently, a wide range of environmental challenges arose, with societies struggling with global climate change, rising seas, increasing desertification, and resulting wildfires, all of which created additional migration and refugee flows. New pandemic diseases spread quickly, often going global before national health organizations could adequately respond. Globalization, previously touted as the remedy for many ills, has clearly benefited some societies. However, unanticipated costs in terms of human rights, workers' rights, environmental indifference, and increased economic competition have created pressures to wall societies off from such negative consequences. In the midst of all these changes, the international system saw the renewal of Great Power competition between the United States, China, and Russia.

These transformations produce new challenges for the study of IR. For example, concepts of national security must move beyond interstate wars, safety from violent harm, or protection of narrowly-defined national interests to include a greater emphasis on economic security and the need for sustainable economic development and an acceptable quality of life. Other human security interests also have greater salience, including protection from dangers like disease, environmental harm, and systematic violations of human 
rights. Scholars from the Global South increasingly question the assumption that North American and European perspectives on IR and IR theory are universally valid. For them, regional or local issues - and values - demand and deserve more attention (Acharya 2014). Finally, new technologies like drones and cyber weapons pose new challenges, not to mention government struggles to manage public expectations in a world that is increasingly connected by smartphones and social media.

Traditional Westphalian notions of state sovereignty have shuddered in the face of these pressures. Governments have struggled to manage challenges from both outside and within. New norms, such as the idea that if a government would not protect its own people then foreign interventions would be legitimate, represent dramatic shifts (not to mention contested concepts). These and other developments have challenged the future of the Liberal International Order, assumptions like the inviolability of military alliance obligations, and the need for regional or global cooperation. In the face of these profound changes and challenges, effective teaching in IR in the twenty-first century must go well beyond the focus of what was taught to prior generations of undergraduate and graduate students.

\section{RENEWING OUR COMMITMENT TO ACTIVE TEACHING AND LEARNING}

Given these dramatic transformations, this seems a propitious time for reflection, reinvention, and recommitment to learner-centered approaches and interactive methods of teaching and learning. Indeed, our discipline has always been shaped by efforts to make sense of and analyze major developments. This has driven both the process and product of our work in the IR classroom. Committed teacher-scholars identify learning objectives and select methods for teaching that reflect a sense of purpose (Kolb; Hutchings, Huber, and Ciccone). This helps students formulate conceptual linkages between theory and real-world examples, both past and present (Shulman; Cusimano), as well as increase retention of knowledge (Jensen; Brock and Cameron).

\section{Why Active Teaching and Learning? Why Now?}

Beyond its implicit appeal to instructors and students, there are good reasons for teacher-scholars to engage with active teaching and learning in IR. First and foremost, participatory approaches to teaching and learning can help us study the complex changes in global politics discussed above. Revisiting our approach to teaching IR should begin with reevaluation of learning objectives for our courses in the twenty-first century. For example, how do we help students learn about trends like globalization and fragmentation, as well as 
challenges in new realms like global health policies and cybersecurity? How should we present information about civil wars, under-studied regions of the world, and diverse cultures and societies?

Changes in global politics in the twenty-first century have fueled innovations in our teaching and learning approaches - from greater attention to post-colonial discourses and social constructivism in the contemporary IR classroom to the study of cybersecurity, transgender rights, and wartime sexual violence. In short, committed teacher-scholars are seizing learning opportunities and identifying new puzzles and new "ways of knowing" about IR in a dynamic period.

Second, advancements in our understanding of the science of learning represent a second inspiration for teacher-scholars to reevaluate our instructional methods. Neuroscience research has underscored the educational value of student engagement. For example, advances in neuroimaging have helped to illuminate the pathways of the brain that are stimulated by specific teaching and learning techniques. Studies show that "multi-modal" or multi-sensory learning can help promote education and retention of knowledge (Mueller and Oppenheimer). Neuroscience tells us that a mixture of exercises in the classroom like speaking, interacting, movement, writing, and listening can help activate memory pathways and allow new information to be physically linked in the body's neural, cognitive, and emotional, and motor pathways (Ward). Results of student ownership and learner-centered pedagogy can be promoting higher order thinking and deep learning (Dubinsky et al.; Blakemore and Frith; Glisczinski).

A third reason to revisit our modes of instruction, which we discuss further below, is diversification of our pedagogical understandings and the expansion of global perspectives on teaching and learning. As our authors discuss throughout this volume, IR is truly becoming more global and open to perspectives from around the world. Voices from the Global South are increasingly contributing to the scholarship on teaching and learning, for example, dramatically expanding the potential for pedagogical innovations. Instructors and students alike are learning more about the power of diverse cultural perspectives and understandings to enrich our worldviews.

\section{Trends in Active Teaching and Learning}

The expansion of the scholarship on teaching and learning (SOTL) in IR over the past two decades has helped promote engagement and activism in the classroom. It has also had a compound effect on the exchange of ideas and the encouragement of teaching and learning through professional development opportunities. For example, one finds a richer SOTL in publications in leading journals on teaching such as International Studies Perspectives and the Journal 
of Political Science Education. And today there are also more teacher-training opportunities in IR than ever before, including the International Studies Association's (ISA) Innovative Pedagogy Conference series and the American Political Science Association's (APSA) Teaching and Learning Conferences. Collectively, these initiatives and other initiatives have helped promote the further development and exchange of ideas.

Instructors in IR are embracing a much wider set of opportunities for student engagement today. For example, they are building on and expanding simulations and games as platforms for innovations in teaching and learning (Brynen and Milante; Glasgow; Usherwood; Dahlgren, Fewnwick, and Hopwood). These can help students deepen conceptual understandings of a particular phenomenon, institutions, or socio-political processes by using student interaction to bring abstract concepts to life (Meibauer and Nøhr; DiCicco; Matzner and Herrenbrück; Evans, Tse, and Baker). Problem-based or case-based learning exercises represent a second popular trend in the modern IR classroom (Savery; Majeski and Stover). These approaches often place real-world problems at the center of the learning process and are designed to foster an atmosphere of student-centered engagement with the issues, while also promoting critical thinking and group problem-solving, or teamwork (Kille, Krain, and Lantis; Krain).

Other trends in active teaching and learning focus on the use of popular culture touchstones, or what Kille, Krain, and Lantis (2019) call "alternative texts," such as films or popular literature to teach important concepts (Glover and Tagliarina; Van Belle; Stump; Sachleben). Among these, film and video are some of the most widely used alternative texts for teaching IR (Lobasz and Valeriano; Lantis; Gregg 1998, 1999; Gibney; Giglio; Cooley and Pennock). In addition, teaching IR today naturally extends beyond the traditional classroom. Not only are conscientious instructors bringing the world "in" to their classes, some are taking students "out" for direct engagement and experiential learning. While off-campus and study abroad semester programs represent the classical approach to this type of immersion and engagement (Lantis and DuPlaga), many instructors also help connect students directly to their wider communities through service-learning (Kille, Krain, and Lantis; Robinson; McIlrath and MacLabhrainn; Krain and Nurse).

\section{INCLUSIVENESS, BROADER PERSPECTIVES, AND GLOBALIZING CONTENT}

A contemporary examination of teaching must also consider how to broaden IR teaching away from exclusively Western and Global North lenses and towards more inclusive and diverse perspectives and practices. Calls for diversity and inclusiveness in IR are not new. They can be traced in part to the 
development of Feminist IR theory as a critical perspective on Realism and other traditional schools of IR thought, as well as challenges from voices in the Global South (Acharya 2014).

Currently, both ISA and the APSA are beginning to address issues of diversity and inclusion more actively as part of their agendas. For example, in 2017, the APSA included the promotion of diversity and inclusion in its 2017-2019 strategic plan and subsequently published its 2018 Diversity and Inclusion Report. At ISA, the program for the 2020 Annual Meeting, "Multiple Identities and Scholarship in a Global IR: One Profession, Many Voices" invited participants to acknowledge and reflect upon the state of the discipline as a product of patriarchal, Western identities and promote discourse and action to diversify the field. The call for papers focused on the need to make space for gender, racial, ethnic, Global South, LGBTQIA+ (lesbian, gay, bisexual, transgender, queer, and intersex), and marginalized group access to the organization and the field. ISA also actively promoted panels on issues surrounding the problems of "Structuring Inclusion/Challenging Oppression" as a part of this program. Nevertheless, significant progress remains if we are to more accurately construct undergraduate and graduate IR courses that truly recognize issues and perspectives from women, minorities, and the Global South that have so often been ignored by mainstream scholarship and pedagogy.

\section{Decolonization and Inclusion of Diverse Perspectives}

The goals of recognizing and incorporating diversity and inclusion into our teaching are both simple and complicated. At its most basic level, inclusivity refers to the act of making space for more individuals and ideas from a wide array of backgrounds, and in a safe, equitable, and respectful manner. Conversations about inclusion and diversity have increasingly focused on the need to "decolonize" the academe, or to "recognize that knowledge is inevitably marked by power relations," (Gopal) and to "scrutinize the colonial and racist foundations and practices of the field of international relations" (Koomen). However, as Koomen and others have noted, students of IR remain primarily exposed only to the traditional, outdated version of IR limited to the -isms and primarily influenced by white, male voices.

While some are invariably threatened by calls for decolonizing IR, it is important to note that efforts to decolonize do not mean erasure of these traditional, elite voices. Rather, the need for decolonization and inclusion reflects the increased awareness that if we do not incorporate the voices and experiences of non-white, non-Western, and non-heterosexual male voices alongside the Anglo-European male experience, we are inevitably limiting our knowledge in both theoretical and empirical terms. If the aim of both research and teaching is to increase knowledge, then we do a disservice if we fail to 
strive for inclusion, diversity, intersectionality - what is effectively decolonization - in our teaching practices. Rather than increase knowledge, we limit it.

\section{Methods and Approaches for Decolonizing IR Teaching}

Fortunately, there is a growing scholarship and conversation devoted to decolonizing the teaching of IR, both for the sake of broadening perspectives and content and because of the need to accurately reflect the experiences and identities of the students we teach. Restructuring syllabi to include more non-white scholarship and to be more critical of our dependence upon the "-isms" is one place to start, as is thinking critically about the content of the textbooks we assign and opting for choices that include diverse perspectives alongside the foundational texts so many rely upon (see Atchison; Baylis, Smith, and Owens; Olivo).

Beyond restructuring course content, purposefully incorporating more readings from women and $\mathrm{POC}$ (people of color) scholars in the subject matter we teach can help to broadly diversify the field of IR. The "gender gap" in IR scholarship has been well-documented (Maliniak, Powers, and Walter; Mitchell, Lange, and Brus). To overcome this gap, not only must we do a better job of citing diverse scholars in our research, we must also normalize the work of women and minorities in the material we teach. If overcoming the gender/ race/ethnic/Global South gap in IR means we must amplify these works in bibliographies, how much more progress can we make if we also include these voices in the foundational educational experiences of future IR scholars, too?

Of course, finding additional strategies to decolonize teaching in thoughtful and pedagogically-informed ways is also important. Engaging students in dynamic classroom practices taught by well-informed teacher-scholars can help enhance student engagement with diverse material and topics to which they were previously not exposed. Some of these approaches include active learning strategies, the assignment of both fiction and non-fiction literature - including novels and biographies - and the use of film and other media (Rasmussen). The use of social media as a vehicle to connect students in the Global North with peers in Global South countries, promoting exchanges of ideas and firsthand interactions that many students would otherwise remain unexposed to is another option (Shaw 2016). "Empathic scaffolding," where students are exposed to diverse perspectives through "content and pedagogy to strategically expand students' zones of comfort from very personal experiences with the material to broader groups of people and course concepts" (Bauer and Clancy, 73), may prove especially useful.

Among such approaches, making individual students responsible for tracing one country, idea, perspective, or issue throughout the course and enabling students to develop more intimate connections with a new and different subject 
allows for greater depth of experience and understanding, which may create long-lasting, empathic effects. Finally, we also note that the burgeoning scholarship on teaching IR from diverse and inclusive perspectives includes a lively online presence of active teacher-scholars regularly experimenting with and sharing ideas that promote active student learning from different and diverse perspectives. Blogs like Active Learning in Political Science and The Tatooed Professor, by historian Kevin Gannon, provide resources for simulations and related exercises that challenge student thinking in new and diverse ways.

In sum, the need to teach IR from and make space within the field of IR for diverse and inclusive voices and perspectives is increasingly pressing. Crossing boundaries and crossing cultures have always been important dimensions of IR training, but there is a greater urgency for attention to these perspectives in twenty-first-century discourses. Today, there are more contributions to dialogues about active pedagogy underway in the profession - and much greater respect for and recognition of the value of these contributions to our discipline. In many ways, this book celebrates this diversity and seeks to further fuel the dialogue in the SOTL on future pathways. If knowledge is the key to combating discrimination, then diversifying and decolonizing our teaching is a task of utmost importance.

\section{A PREVIEW OF WHAT FOLLOWS}

Our volume is organized into three sections: Contemporary Trends in Course Structures and Goals; Innovations in the Classroom: Techniques and Approaches; and Assessment and Effectiveness. The contents are designed to capture important trends in pedagogy and contribute a continuing dialogues on pedagogy in the field.

The remainder of the volume proceeds as follows. In Part I: Contemporary Trends in Course Structures and Goals, our contributors focus on course structure and goals. It includes chapters that provide broad overviews of theories of learning and pedagogy and identifies prominent themes to be explored in the IR classroom. In Chapter 2, Paul F. Diehl and Mark A. Boyer address the essentials of introductory IR courses, while Jeffrey S. Lantis discusses learning goals, engagement, and outcomes in Chapter 3. In Chapters 4 and 5, Jacqueline de Matos Ala, Cristina Yumie Aoki Inoue, and Marcelo Valença focus on teaching IR in the Global South, while Dovilè Budryte focuses on on feminist approaches and intersectionality.

Part II: Innovations in the Classroom: Techniques and Approaches contains ten chapters that feature contributions on active and engaged approaches, techniques, and activities, grounded in the scholarship of teaching and learning. Ralph G. Carter discusses teaching with case studies in Chapter 6. Amy Below, Mandy Nydegger, and Mary Jane Permentier consider the 
nature and opportunities of faculty-led study abroad in Chapter 7. The next two chapters feature a discussion of teaching with Statecraft, an online simulation, by Eric Cox (Chapter 8), and the use of simulations and games more broadly by Amanda Rosen and Victor Asal (Chapter 9). Eric Leonard takes on the use of IR theory in Chapter 10, while Gigi Gokcek and Patrick James discuss the use of literature and film to teach IR in Chapter 11. James M. Scott then takes up problem-based and research-focused approaches to teaching (Chapter 12), while Yasemin Akbaba and Filiz Başkan devote their attention to using technology to teach cross-cultural diversity in Chapter 13. Continuing the technology topic, Brandy Jolliff Scott explores teaching IR online in Chapter 14. Heather A. Smith concludes this part with her chapter on collaborative learning (Chapter 15).

In Part III: Assessment and Effectiveness, we bring our volume to a close and focus on approaches to assessing teaching effectiveness and learning outcomes. Matthew Krain and Kent J. Kille discuss assessment and effectiveness of Learning in IR Courses in Chapter 16. Kerstin Hamann then addresses the role of asessment in active teaching and learning in Chapter 17.

We hope you find the contents of our volume helpful. 